\title{
Influence of Pushing and Pulling the Electrode Procedure and Addition of Second Layer of Welding on the Wear in Hardfacing of Fe-Cr-C
}

\author{
Romulo Poderoso Rauta ${ }^{a}$, Samuel Filgueiras Rodrigues ${ }^{a, b *}$, Valdemar Silva Leal $^{a}$, Gedeon Silva Reis ${ }^{a}$, \\ Clodualdo Aranas Jr', Valtair Antônio Ferraresi ${ }^{c}$
}

\begin{abstract}
${ }^{a}$ Programa de Pós-graduação em Engenharia de Materiais - PPGEM, Department of Mechanic and Materials, Federal Institute of Education, Science and Technology of Maranhão - IFMA, Av. Getúlio Vargas, $n^{\circ}$ 04, Monte Castelo, 65030-005, São Luís, MA, Brazil

${ }^{b}$ Department of Materials Engineering, McGill University, Wong Building, 3610, University St. H3A 2B2, Montreal, Quebec, Canada

'Department of Mechanic Engineering, Federal University of Uberlâdia, Av. João Naves de Avila, 212, Campus Santa Mônica, CX 593, 38400-902, Ubelândia, MG, Brazil
\end{abstract}

Received: March 18, 2016; Revised: June 08, 2016; Accepted: August 20, 2016

\begin{abstract}
The aim of this work is evaluate the influence of welding conditions on abrasive wear resistance in coating of Fe-Cr-C. The metal base used in this investigation was the steel SAE 1020 and as welded metal the selfshilded tubular wires of $\mathrm{Fe}-\mathrm{Cr}-\mathrm{C}$ with $1.6 \mathrm{~mm}$ of diameter. The welding parameter such as amperage, voltage, welding speed, wire feed speed and the distance between the point and samples were kept constant by varying the electrode inclination and the number of layers deposited. These resulted in four different weld conditions: pulling and pushing the weld pool and hardfacing formed with 1 end 2 layers. Their influences on dilution, microhardness and microstructure were evaluated and correlated with the abrasive wear according to the standard tests methods for abrasion measurements through the usage of dry sand/rubber wheel apparatus, ASTM G-65-04. The results showed that the wear resistance of the four different conditions was affected by dilution, microstructure morphology and carbide volume fraction. The best conditions for hardfacing deposition were for pushing the torch and two layers added.
\end{abstract}

Keywords: Abrasive wear, hardfacing, microstructure

\section{Introduction}

In maintenance, the weld process can be used as a tool to reduce the number of corrective shutdowns and increase the availability of equipment for operation. With the application of weld, critical areas of some equipment can be hardfaced by applying alloys with improved wear resistance thereby reducing the number of stoppages.

The study of the factors which influence the weld wear resistance of applied metals on some equipment contributes to improve the quality of commercial alloys used for this purpose. Thus, welding processes application have been increasing for maintenance purposes and more engineering departments in companies have used this tool for equipment projects that will be subjected to severe wear conditions. An ordinary method against abrasive wear on metals, technically referred as hardfacing, is the application of a special alloy on a metal surface subjected to wear process by the deposition of weld beads. This method is currently being used quite effectively ${ }^{1-3}$

The hardfacing is the application of a hard metal with considerable wear resistant on the surface of a component by

*e-mail: samuel.filgueiras@ifma.edu.br welding, metallization or combination of welding processes with the aim to reduce the material loss by abrasion, impact, erosion, surface slip and cavitation ${ }^{4,5}$. The abrasive wear can be cause by high and low stresses ${ }^{6}$. For the first one, the abrasive wear occurs when the surface of a component is subjected to a constant contact with a granulated material flow. For the second one, the wear occurs when particles is forced to pass under high pressure through some narrow space promoting the forced contact between these particles and part of the equipment. For low stresses abrasion, alloys containing chromium carbides are the most suitable, whereas in the case of high stresses abrasion, it is recommended to use austenitic-martensitic alloy, martensitic steels and some alloys which form small carbides, i.e. chromium carbide ${ }^{7,8}$.

The alloy microstructure for hardfacing application consists of a combination of carbide in a high hardness austenitic matrix providing abrasion resistance to low and high stresses 9 . However, under impact conditions, such as crushers, mills, or intersections railway these alloys become less effective. In this case, it is very important to combine the wear resistance and impact with the commitment to select alloys or working techniques that promote these both functions. Talking in terms of working techniques, the application of 
hardfacing welding by tubular wire has shown the high capacity to produce layers free of defects and has been greatly applied in the industry. Among the other processes, this technique has been acquiring reasonable preference due to its versatility combined with high productivity ${ }^{10-12}$.

It is well known that the abrasive wear resistance is strongly influenced by the characteristics of the hardfacing such as dilution, hardness and microstructure. Therefore, the wear can be discussed based on these characteristics. In general, the commonly alloys used in order to prevent the abrasive wear belong to the $\mathrm{Fe}-\mathrm{Cr}-\mathrm{C}$ system due to their low cost and easy way of application. Low dilution is desired for low influence on hardfacing composition and final properties avoiding contamination from the metal base $\mathrm{e}^{13}$. For this type of alloy, these characteristics are variable and depend on electrode inclination and number of deposited layers.

Within the context above, the aim of this work was to investigate the effect of electrode inclination in 15 degree for two different situations on the abrasive wear resistance, pushing and pulling and moreover the effect of layers quantity on a SAE 1020 steel.

\section{Materials and methods}

\subsection{Welding procedure}

The welds were performed by using universal multiprocess source 600 , a wire feeder BMI STA120, a torch cooled by water, and a coordinate table whose function was to shift the torch and keeping the welding parameters constant. For added metal or coating material, it was used a tubular wire selfshilded $1.6 \mathrm{~mm}$ in diameter whose chemical composition is shown in Table 1.

Table 1: Chemical composition and hardness of the tubular wire

\begin{tabular}{llllll}
\hline \multirow{2}{*}{ Wire } & Hardness & \multicolumn{5}{c}{ Composition [\%] } \\
\cline { 3 - 6 } & $\left(\mathrm{HR}_{\mathrm{C}}\right)$ & $\mathrm{C}$ & $\mathrm{Cr}$ & $\mathrm{Mn}$ & $\mathrm{Si}$ \\
\hline \multirow{2}{*}{ FeCrC } & 59 to 61 & 4.11 & 23.1 & 0.52 & 0.2 \\
\hline
\end{tabular}

As metal base for preliminary tests and application of hardfacing material, ABNT 1020 carbon steel plates were used in dimensions of 200x40×12 mm.

To investigate the influence of the inclination by "pulling", the electrode was inclined at 15 degrees and the direction of welding occurred pulling the weld pool. To "pushing", the electrode was kept at 15 degrees and the direction of welding was given by pushing the weld pool. A schematic detail of this of theses selected process parameters are shown in Figure 1. In both cases the welding direction was the same, but the torch inclination directions were given in opposite order. Moreover, to study the influence on the quantity of layers, "layer 1" means that the hardfacing was performed in order to form just one layer of weld on base metal, and "layer 2", one more weld layer was added on the previous one already formed. For the last two conditions the electrode was kept perpendicular to the metal base surface and all other parameters listed in Table 2 remained constant.

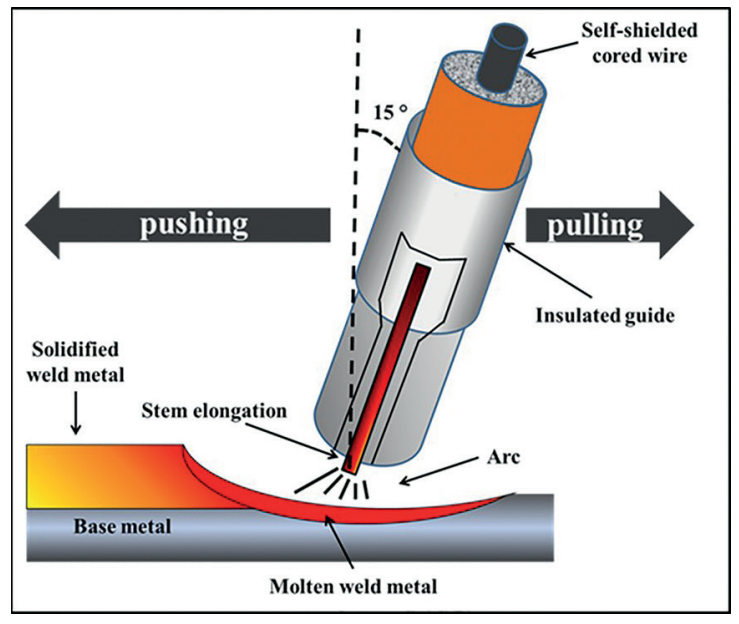

Figure 1: Schematic detail of the procedures "pushing" and "pulling" the torch with electrode inclined at 15 degree.

Table 2: Welding Parameters

\begin{tabular}{lc}
\hline Wire speed feeding & $7,6 \mathrm{~m} / \mathrm{min}$. \\
\hline Weld speed & $475 \mathrm{~cm} / \mathrm{min}$. \\
Voltage & 26 Volts \\
Current & 315 Amperes \\
DBEM* $^{*}$ & $25 \mathrm{~mm}$ \\
\hline
\end{tabular}

\subsection{Samples preparation}

The samples for wear and hardness measurement were taken from the central region of the welded plates. The hardfacing were rectified on surface until appear uniformed to obtain the standardized dimensions $(25 \times 75 \times 10 \mathrm{~mm})$ according to ASTM G65-04 ${ }^{14}$. For each welding condition, samples were also taken to measure the weld bead dilution. They were prepared by cutting the cross section of the welded bar, whose section was polished and etched with Nital during 10 seconds, thereby highlighting the edges of the weld beads.

Also, samples from the center of the welded plates were extracted in order to carry out microhardness and microstructure analysis. Figure 2 shows a scheme of the sample geometry and selected area for microhardness and wear properties tests ${ }^{15}$. These samples were cut, sandpapered with 180-1000 grinding and polished with diamond paste $3 \mu \mathrm{m}, 1 \mu \mathrm{m}$ and $0,25 \mu \mathrm{m}$. For the revelation of carbides, Murakami reagent was used at $60{ }^{\circ} \mathrm{C}$ during 10 seconds. 


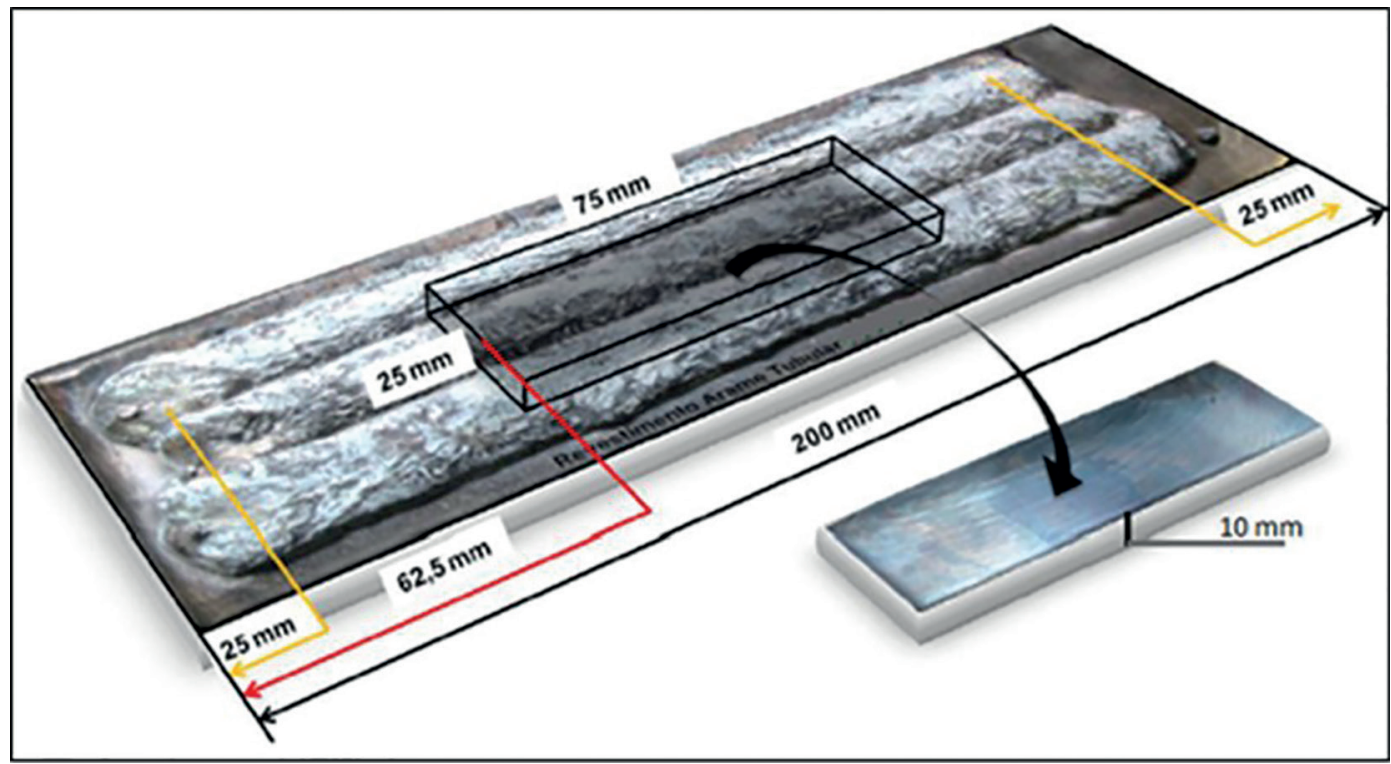

Figure 2: Scheme of the sample geometry and selected area for microhardness and wear properties tests ${ }^{15}$.

\subsection{Wear tests}

Wear tests were performed in an abrasion machine using a rubber wheel under dry condition constructed according to ASTM 65-04, shown in Figure 3. This equipment is recommended for abrasive wear simulation under low stresses (Test type B following the standard ASTM G65-00) ${ }^{14}$. Table 3 shows the abrasion tests parameters according to the followed standard. The wears were evaluated in terms of the specimens weight loss by comparing the weight before and after the test on an electronic weighing machine with resolution of $10^{-5} \mathrm{~g}$.

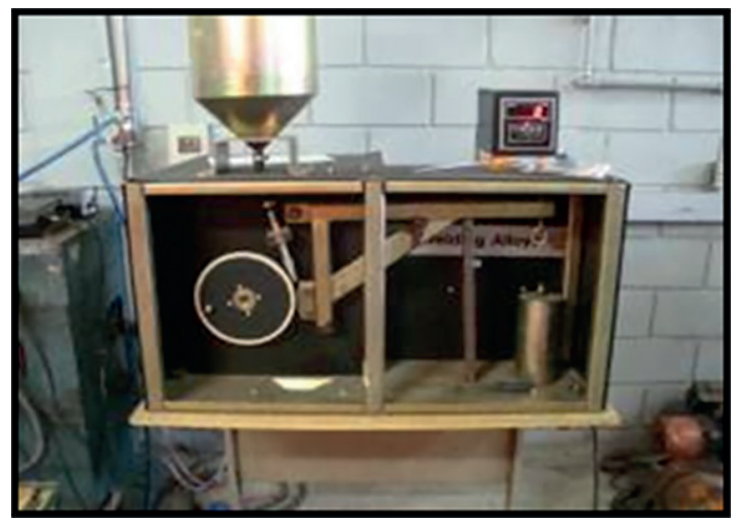

Figure 3: Rubber wheel abrasion resistance machine used to simulating the low stress abrasion.

For dilution verification, the samples were photographed with a digital camera and analyzed by Image J software. This analyses allowed data evaluation necessary to calculate the weld bead dilution, such as: Reinforcing area $\left(\mathrm{S}_{\mathrm{ad}}\right)$, molten area $\left(\mathrm{S}_{\text {fund }}\right)$, reinforcement height $\left(\mathrm{R}_{\mathrm{ef}}\right)$, penetration $\left(\mathrm{P}_{\mathrm{n}}\right)$ and width (L), as shown in Figure 4.
Table 3: Abrasion tests parameters according to the standard ASTM 65-04.

\begin{tabular}{ll}
\hline Disk Dimension & $12.7 \times 228 \mathrm{~mm}$ \\
\hline Rubber wheel hardness / thickness & 60 Shore A / $12.7 \mathrm{~mm}$ \\
Brazilian standard $\mathrm{n}^{\circ} 100$ for sand & $0.15 \mathrm{~mm}$ \\
Disk rotation & $200 \mathrm{RPM}$ \\
Tests time & $15 \mathrm{~min}(5$ min pre-loading \\
Load & and 10 min of wear) \\
Travel distance & $130 \mathrm{~N}$ \\
\hline
\end{tabular}

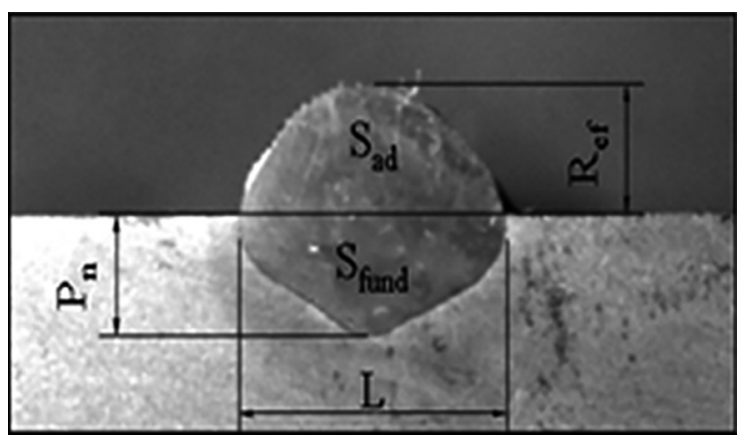

Figure 4: Weld bead image on a layer and the components to calculate the dilution ${ }^{6}$.

The dilution calculation was done by the relationship between the welded area and the total area of the weld bead, according to equation 1 .

$$
\text { Dilution }=\frac{S_{\text {fund }}}{S_{a d}+S_{\text {fund }}}
$$


The microhardness was obtained following the standard NBR 6672.

The microstructures images were obtained by SEM and the carbides volumetric percentage was calculated by Image pro plus software that allows, among other things, manipulate images and make statistical studies regarding to the phases presented.

\section{Results and Discussion}

Figures 5 and 6 show the results of weight loss and dilution respectively considering the influence of pulling and pushing weld pool, one layer and two layers of hardfacing deposited on the metal.

It is observed that for pulling the weld pool procedure, there were higher weight loss and dilution than for pushing the weld pool. The same behavior occurred for the one layer of hardfacing deposited showing more weight loss and dilution than for two deposited hardfacing on the metal base. The highest wear occurs in situations of higher dilution as well as higher heat input, contributing for higher weight loss for low stress abrasive condition for $\mathrm{Fe}-\mathrm{Cr}-\mathrm{C}$ deposits which suffered considerable dilution. When there is high degree of mixing between the metal base and added metal, which occurred in the case of pulling the torch due to higher dilution, weld metal properties are closer to the metal base, worsening the quality of hardfacing.

According to Buchely et al. ${ }^{16}$, the wear in the first layers is often greater than in subsequent layers. One second layer strongly contribute to low dilution whereas the second layer is formed on the welded metal itself and is expected to reduce contamination from metal base with one layer separating both. It was verified that the application of second layer improved the hardfacing wear resistance in terms of weight loss and this is in accordance with previous investigations ${ }^{17}$.

Bear in mind that when evaluating the microstructure, the hardness of the phases as well as the quantification of them and the morphology of the precipitates are important factors that must be evaluated in order to study the abrasive wear. Different morphologies and quantities of those precipitates rounded by eutectic matrix are presented in Figure 7.

The microstructures shown a considerably amount of primary carbides, $\mathrm{M}_{7} \mathrm{C}_{3}$ type (darker region) confirmed by FactSage calculation using FSteel data base, Figure 8, and later by EDX. These carbides are involved by a light region named eutectic matrix. It is noteworthy in Figure 7(a) for pulling procedure, that the eutectic matrix is formed by small carbides and the primary $\mathrm{M}_{7} \mathrm{C}_{3}$ type carbide are presented in

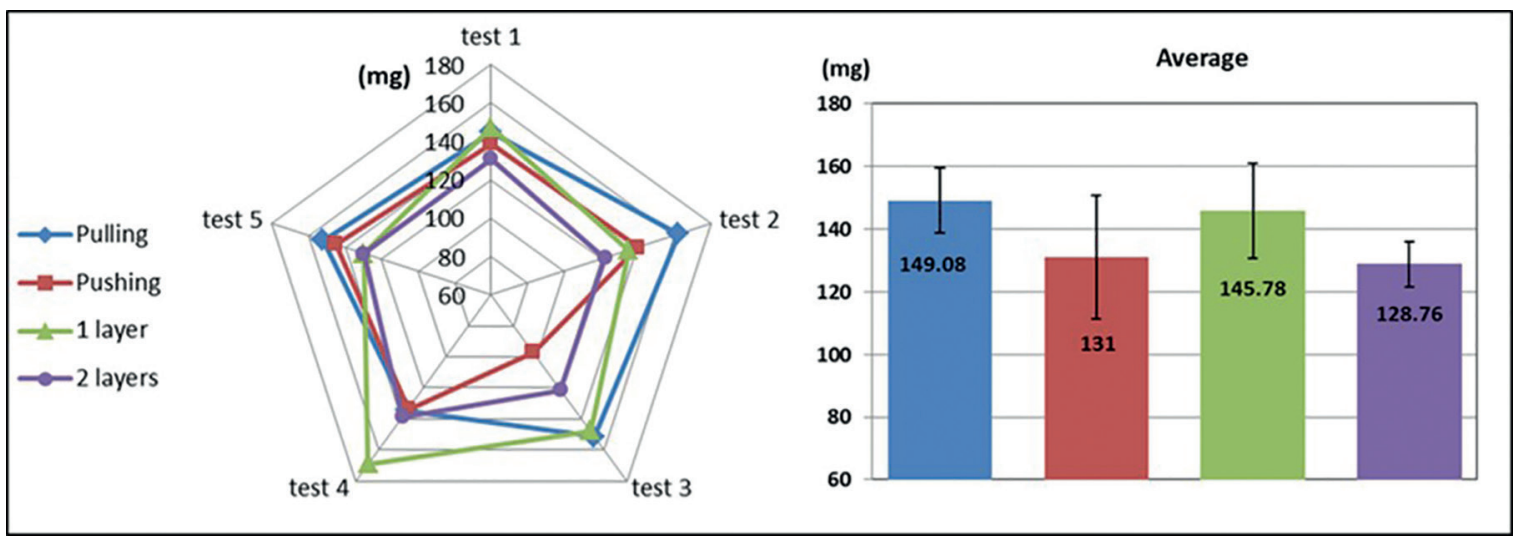

Figure 5: Weight loss of the samples subjected to abrasion tests

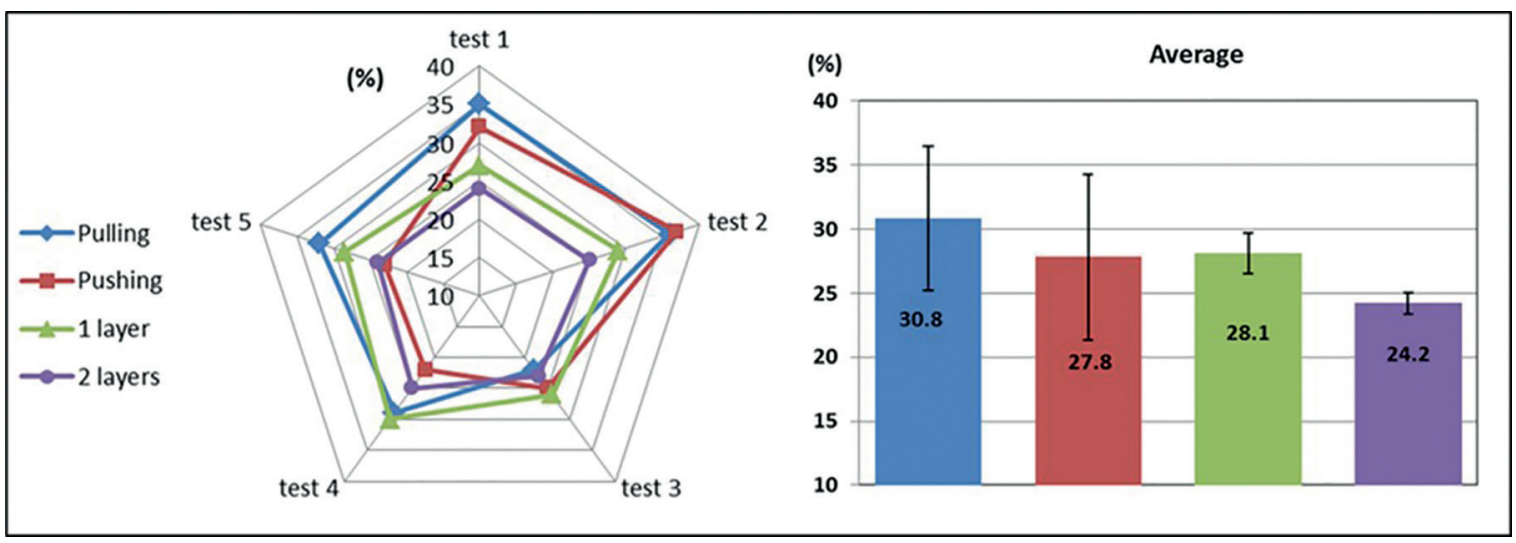

Figure 6: Dilution percentage of the samples calculated according to equation 1. 


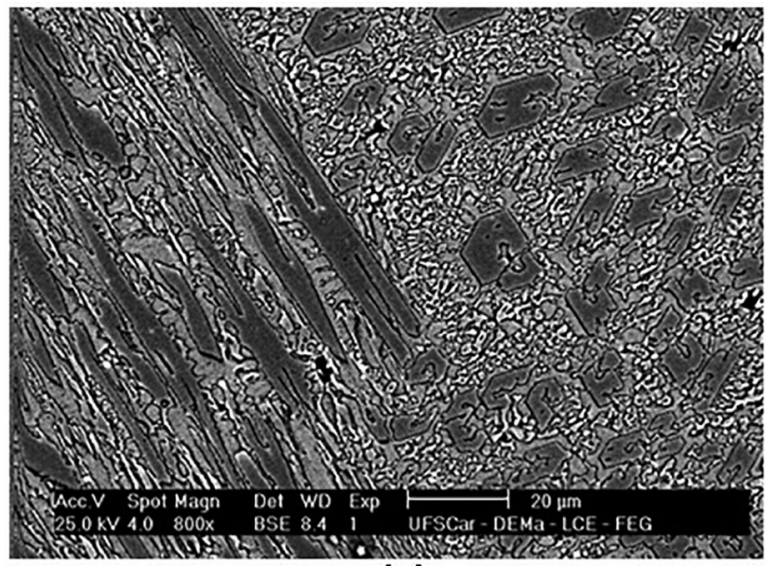

(a)

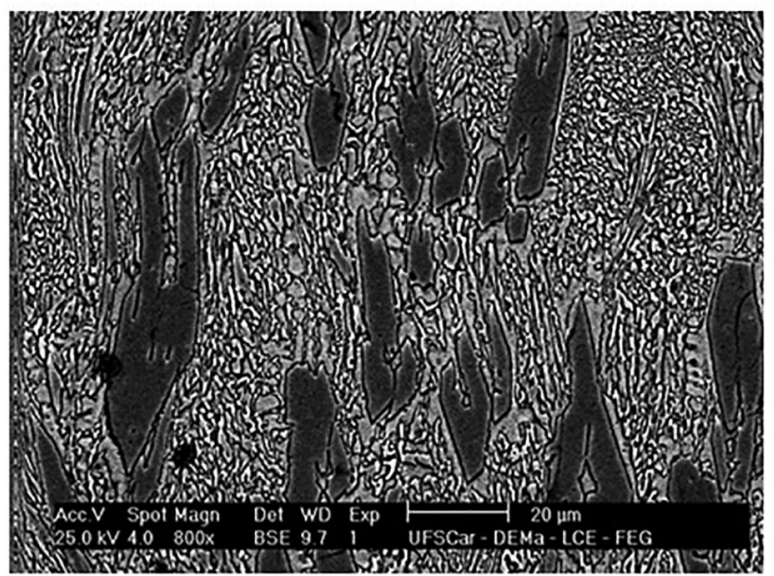

(c)

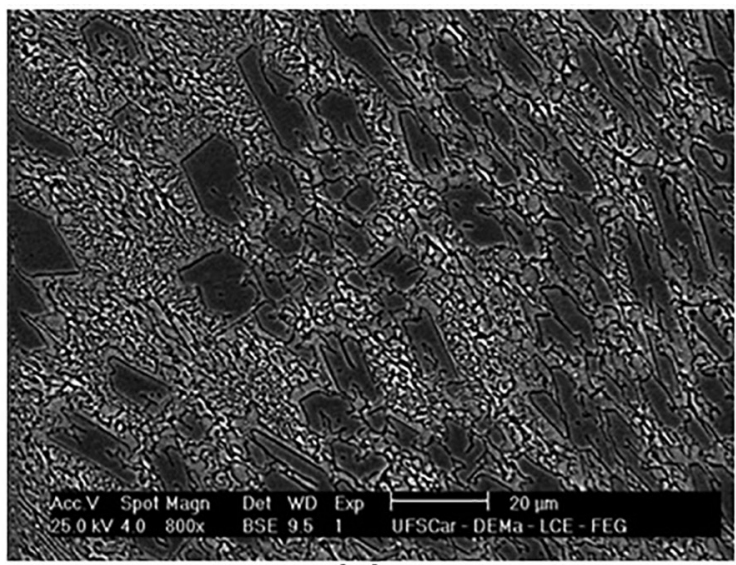

(b)

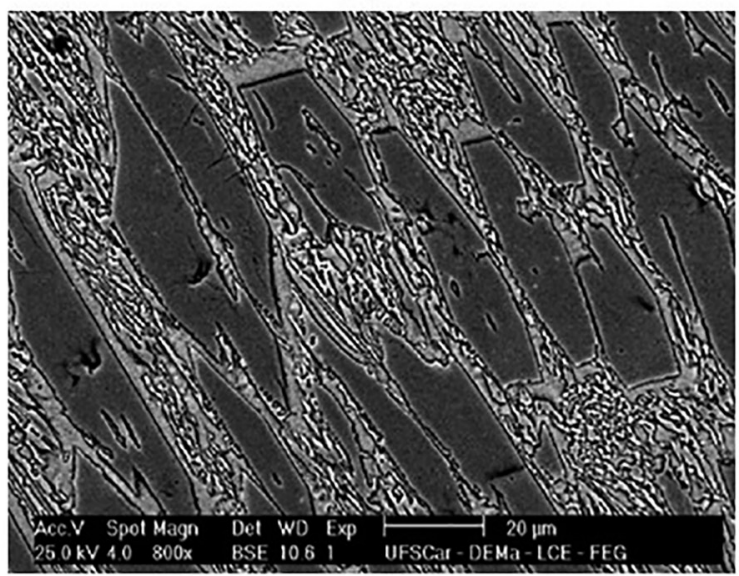

(d)

Figure 7: SEM of the Fe-Cr-C hardfacing for (a) pulling the torch, (b) pushing the torch, (c) one deposited layer and (d) two deposited layers.

elongated shapes as well as in compact forms (dark phase). It is important to emphasize that the elongated shape can exceed $70 \mu \mathrm{m}$ in length and compact ones present larger sizes close to $20 \mu \mathrm{m}$. In Figure 7(b) for pushing procedure, the microstructure is quite similar to the first one but without the presence of elongated carbides and predominance of compact carbides and in more quantity. Figure 7(c) for one layer deposited, there is a large area for the eutectic matrix that is formed by small precipitates carbides and homogeneously dissolved in an austenitic phase (light phase). Furthermore, the dark phases formed by primary carbides are in irregularly shape. In Figure 7(d) for two deposited layers, it is observed high proportion of large compact carbides that can exceed $70 \mu \mathrm{m}$ in length.

EDS technique was applied on eutectic matrix and on the primary carbides in order to identify the elements pertaining to these phases. Figures 9 (a) and (b) display the chemical analysis of the eutectic matrix and primary carbides, respectively. On eutectic matrix, Fe content is greater however, it is noted the presence of $\mathrm{Mn}$ and $\mathrm{Cr}$, which indicates small amount of carbides of these elements present in the matrix. On the primary carbides region, peaks of $\mathrm{Cr}, \mathrm{Fe}$ and $\mathrm{Mn}$ are

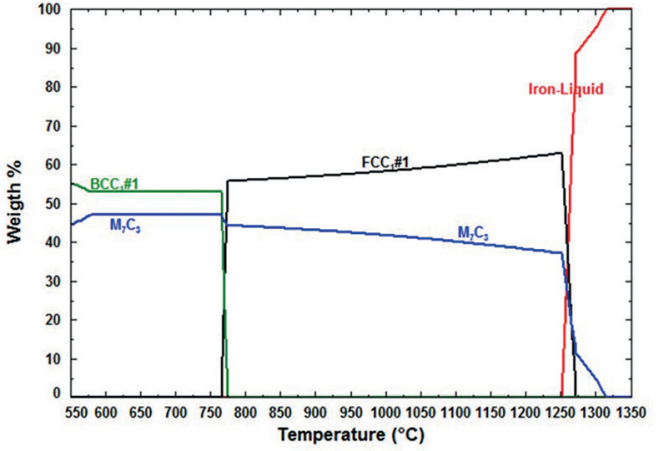

Figure 8: Equilibrium diagram for the $\mathrm{FeCrC}$ wire used as hardfacing added metal.

observed in descending order of concentration. According to FactSage calculation, the primary carbides composition is about $56.82 \% \mathrm{Cr}_{7} \mathrm{C}_{3}-41.95 \% \mathrm{Fe}_{7} \mathrm{C}_{3}-1.23 \% \mathrm{Mn}_{7} \mathrm{C}_{3}-12.23 \% \mathrm{Mn}_{7} \mathrm{C}_{3}$. It well known that these elements in combination improve the corrosion resistance and normally stabilize the structure for applications at high temperatures. 


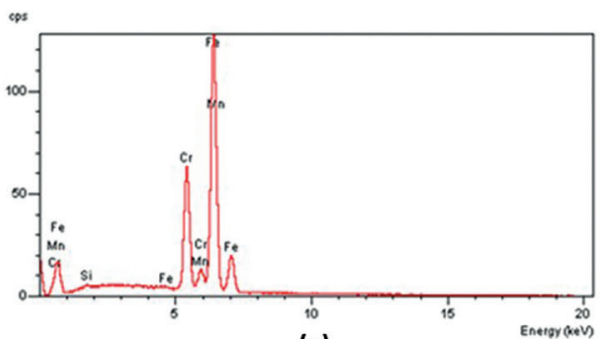

(a)

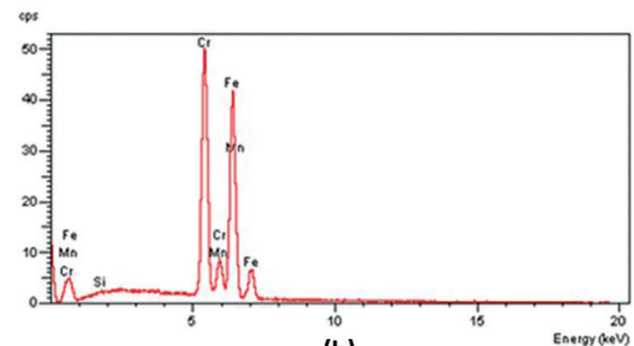

(b)

Figure 9: EDS of the Fe-Cr-C hardfacing on (a) eutectic matrix and (b) primary carbides.

By X-ray diffraction pattern on the welded sample with two layers, Figure 10, it can be noted that the predominant carbides $\mathrm{Cr}_{7} \mathrm{C}_{3}$ type present a peak of $62.50 \%$, while the presence of $\mathrm{Fe}_{7} \mathrm{C}_{3}$ and $\mathrm{Mn} 7 \mathrm{C}_{3}$ types are limited to peaks up to $33.33 \%$. The EDX pattern for the others three conditions analyze here is not shown but they presented similar parameters as for two layers with slight differences that can be neglected.

During the analysis made so far, worth mansion that the microstructures of the samples are formed by the same phases, carbides $56.82 \% \mathrm{Cr}_{7} \mathrm{C}_{3}-41.95 \% \mathrm{Fe}_{7} \mathrm{C}_{3}-1.23 \% \mathrm{Mn}_{7} \mathrm{C}_{3}$ (darker phase) and an eutectic phase and small precipitates of carbides, however, with differences in morphology, amount and size of these precipitates. These contributed decisively to the wear differences found on the four conditions.

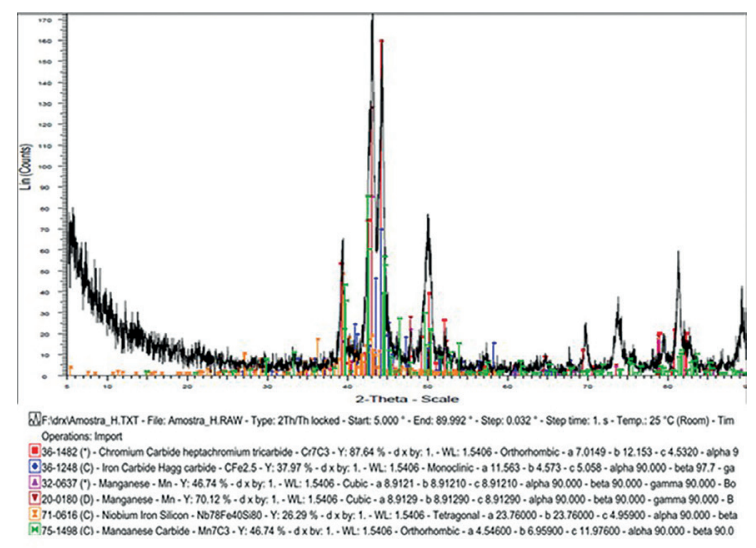

Figure 10: EDX of the welded sample containing two deposited layers (coating surface).

Additionally, microhardness test on the eutectic matrix and primary carbides volume fraction calculation were done in order to compare and make correlation between the weight loss, dilution percentage and microstructures. 6 microhardness measurements were done on each sample and 10 images were used to calculate the volume fraction of carbides from each sample. Figure 11 displays the microhardness average values on left $Y$ axe and the carbide volume fraction average values on right $Y$ axe from each of the four conditions applied

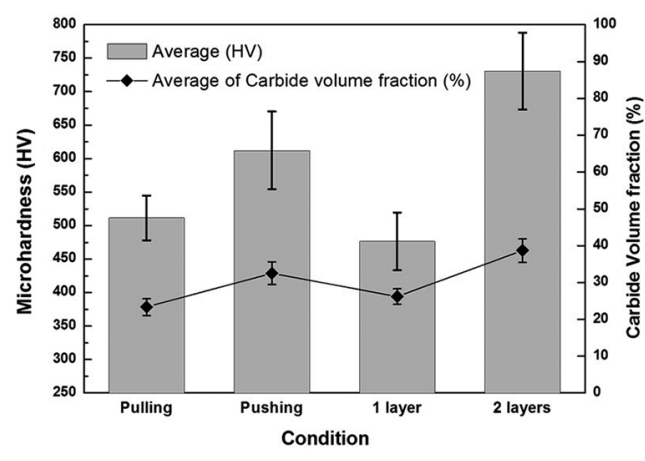

Figure 11: Microhardness, left $Y$ axe, of the samples under the four different conditions and their corresponding Carbide volume fraction, right $\mathrm{Y}$ axe.

in this research. It can be seen that, pushing and 2 layers presented higher values of microhardness as well as carbide volume fraction. Whereas the expected value for the isolated austenitic phase microhardness is $350 \mathrm{HV}^{17}$, higher values obtained for the four experimental conditions indicates that the penetrator has also reached the carbides. These values are in agreement with the weight loss and dilution. It can be seen that the condition with 02 layers showed a greater amount of carbides, about $38.7 \%$, confirming the morphology presented in Figure 7. It can be inferred that, welds presenting elevated quantity of eutectic matrix and lower carbide volume fraction are always subjected to greater wear.

Figure 12 presents the wear trails for the pulling (Figure 12a), pushing (Figure 12b), 1 layer (Figure 12c) and 2 layers (Figure 12d). It is observed that for the condition of pulling the torch, Figure 12(a), there are deeper furrow and in more quantity, while that for pushing, Figure 12(b), shows continuous and more homogeneous furrow. For the former case, in consequence of presenting the lower dilution, greater amount of carbides and consequently lower area of eutectic matrix, the plastic deformation is less apparent than the first case. By pulling the weld bead procedure, the amount of eutectic microconstituents is higher the abrasive penetration becomes deeper. In the condition where were added just one 


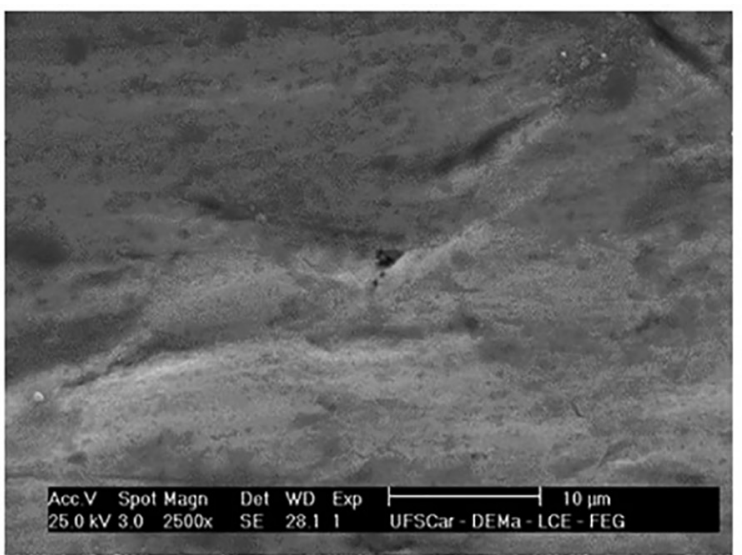

(a)

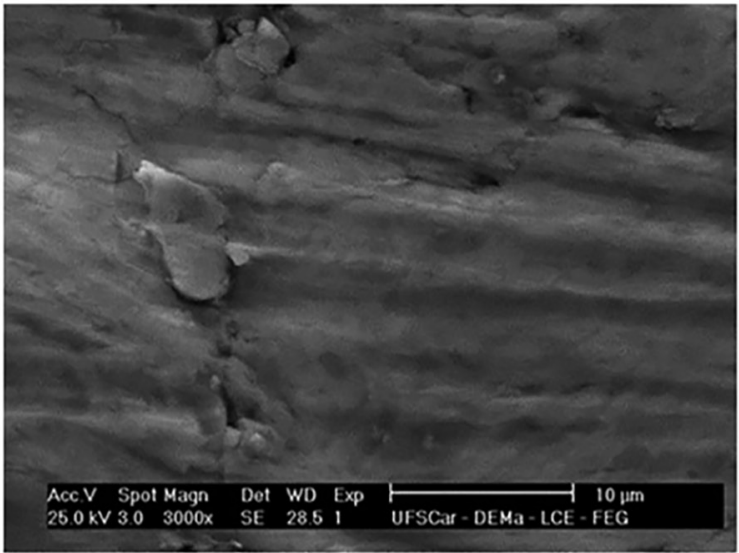

(c)

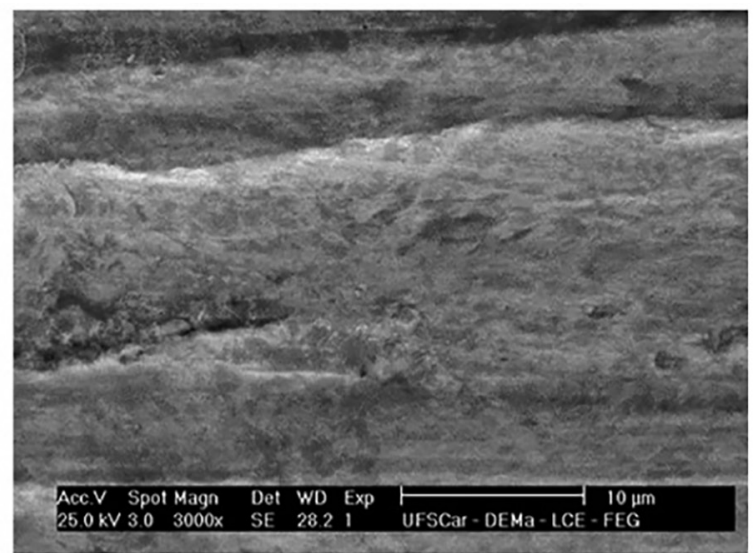

(b)

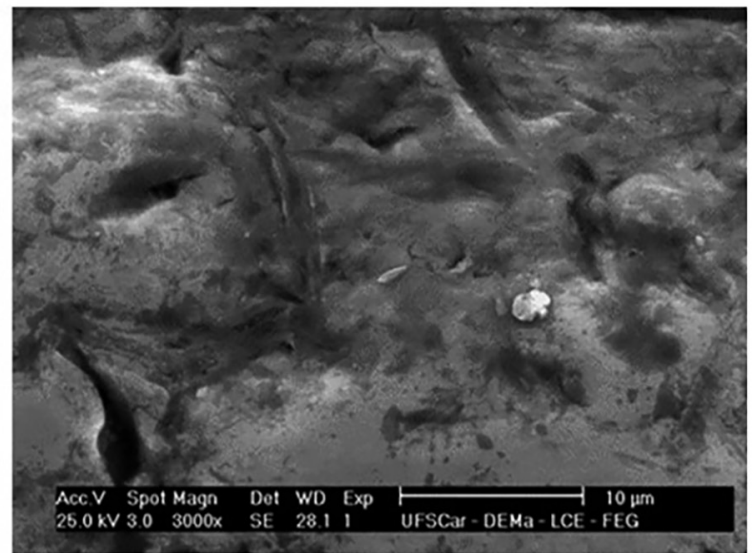

(d)

Figure 12: Wear trails for conditions of (a) pulling the torch, (b) pushing the torch, (c) one deposited layer and (d) two deposited layers.

welded layer, Figure 12(c), it can be seen deep wear furrows. For two added weld layers, Figure 12(d), it is remarkable the absence of wear trails. This is probably due to the large amount of compact carbide and well supported by the matrix preventing the action of continuous coating weigh loss.

In this research, only small changes in chemical composition and microconstituents coatings happened due to the four welding conditions, however, the size, shape, distribution and amount of microconstituents are directed related to the variation of welding conditions. In this manner, the mechanisms of abrasive wear conditions present in pushing and pulling the weld bead as well as for one and two deposited layers can be explained based on, for example, the amount of exposed eutectic matrix to abrasive particles and moreover the amount and morphology of the carbides resulting from each experimental condition.

\section{Conclusions}

The four techniques applied here have significant influence on the wear resistance for the low stresses abrasive tests on Fe-Cr-C hardfacing.
The wears were lower for the conditions when the torch was pushed and two layers were deposited. These were favored for the low dilution and the presence of more compacted primary carbides.

The microstructure proved to be the main factor of evaluation to investigate the wear resitence under the four conditions imposed here. This microstructure is directly resulted from the amount, morphology and hardness of $\mathrm{M}_{7} \mathrm{C}_{3}$ carbides type.

The main wear mechanism found was to microfurrow presented mainly under the pulling the weld bead and with just one deposited layer.

\section{Acknowledgements}

The authors thank the Brazilian research funding agencies FAPEMA (Maranhão Foundation for Scientific Research and Development) and CNPq (National Council for Scientific and Technological Development). They would also like to acknowledge Prof. In-Ho Jung from McGill University for providing access to FactSage thermodynamic software. 


\section{References}

1. Ramalingam S, Wright PK. Abrasive wear in machining: experiment with materials of controlled microstructure. Journal of Engineering Materials and Technology. 1981;103(2):151-156.

2. Park KH, Kwon PY. Flank wear of multi-layer coated tool. Wear. 2011;270(11-12):771-780.

3. Cardoso PHS, Israel CL, Strohaecker TR. Abrasive wear in Autempered Ductile Irons: A comparison with white cast irons. Wear. 2014;313(1-2):29-33.

4. Henderson JL, Bulloch JH. Alloy classification of hardfacing materials. International Journal of Pressure Vessels and Piping. 1991;47(2):127-158.

5. Buchanan VE, Shipway PH, McCartney DG. Microstructure and abrasive wear behavior of shielded metal arc welding hardfacings used in the sugarcane industry. Wear. 2007;263(1-6):99-110.

6. Santos MB, Labiapari WS, Ardila MAN, da Silva WM Jr, de Mello JDB. Abrasion-corrosion: New insights from force measurements. Wear. 2015;332-333:1206-1214.

7. Liu C, Leyland A, Bi Q, Matthews A. Corrosion resistance of multilayered plasma-assisted physical vapour deposition $\mathrm{TiN}$ and $\mathrm{CrN}$ coatings. Surface and Coatings Technology. 2001;141(2-3):164-173.

8. Ahn SH, Choi YS, Kim JG, Han JG. A study on corrosion resistance characteristics of PVD $\mathrm{Cr}-\mathrm{N}$ coated steels by electrochemical method. Surface and Coatings Technology. 2002;150(2-3):319-326
9. Zum Gahr KH, ed. Microstructure and Wear of Materials. Amsterdam: Elsevier; 1987. 560 p.

10. Badisch E, Katsich C, Winkelmann H, Franek F, Roy M. Wear behavior of hardfaced $\mathrm{Fe}-\mathrm{Cr}-\mathrm{C}$ alloy and austenitic steel under 2-body and 3-body conditions at elevated temperature. Tribology International. 2010;43(7):1234-1244.

11. Bergman F, Hedenqvist $P$, Hogmark S. The influence of primary carbides and test parameters on abrasive and erosive wear of selected PM high speed steels. Tribology International. 1997;30(3):183-191.

12. Berns H, Fischer A. Tribological stability of metallic materials at elevated temperatures. Wear. 1993;162-164(Part A):441-449.

13. Kannan T, Murugan N. Effect of flux cored arc welding process parameters on duplex stainless steel clad quality. Journal of Materials Processing Technology. 2006;176(1-3):230-239.

14. ASTM International. ASTM G65-04 - Standard Test Method for Measuring Abrasion Using the Dry Sand/Rubber Wheel Apparatus. West Conshohocken: ASTM International; 2010.

15. Garcia DBC. Aplicação de revestimento duro utilizando o processo arame tubular com e sem adição de arame não energizado para diferentes tipos de consumiveis. [Dissertation]. Uberlândia: Universidade Federal de Uberlândia; 2011.

16. Buchely MF, Gutierrez JC, León LM, Toro A. The effect of microstructure on abrasive wear of hardfacing alloys. Wear. 2005;259(1-6):52-61.

17. Léon Sevilla LM, Gutierrez Pineda JC, Toro A. Relación microestructura resistencia al desgaste de recubrimientos duros ricos en cromo y tungsteno, aplicados por soldadura electrica (SMAW). Dyna. 2004;71(144):165-171 